\title{
Biological Evaluations of an Off-Stream Channel, Horizontal Flat-Plate Fish Screen-The Farmers Screen
}

Open-File Report 2010-1042 



\section{Biological Evaluations of an Off-Stream Channel, Horizontal Flat-Plate Fish Screen-The Farmers Screen}

By Matthew G. Mesa, Brien P. Rose, and Elizabeth S. Copeland

Open-File Report 2010-1042 


\section{U.S. Department of the Interior \\ KEN SALAZAR, Secretary}

\section{U.S. Geological Survey \\ Marcia K. McNutt, Director}

U.S. Geological Survey, Reston, Virginia: 2010

For more information on the USGS-the Federal source for science about the Earth, its natural and living resources, natural hazards, and the environment, visit http://www.usgs.gov or call 1-888-ASK-USGS.

For an overview of USGS information products, including maps, imagery, and publications, visit $h$ ttp://www.usgs.gov/pubprod

To order this and other USGS information products, visit http://store.usgs.gov

Suggested citation:

Mesa, M.G., Rose, B.P., and Copeland, E.S., 2010, Biological evaluations of an off-stream channel, horizontal flatplate fish screen-The Farmers Screen: U.S. Geological Survey Open-File Report 2010-1042, 18 p.

Any use of trade, product, or firm names is for descriptive purposes only and does not imply endorsement by the U.S. Government.

Although this report is in the public domain, permission must be secured from the individual copyright owners to reproduce any copyrighted material contained within this report. 


\section{Contents}

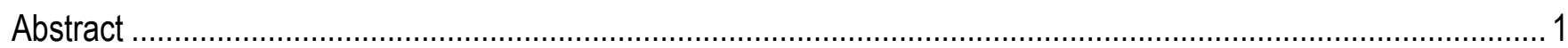

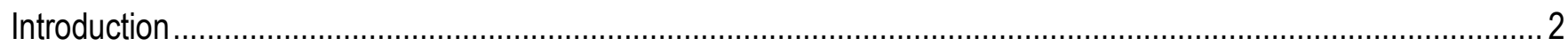

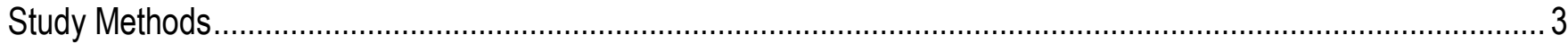

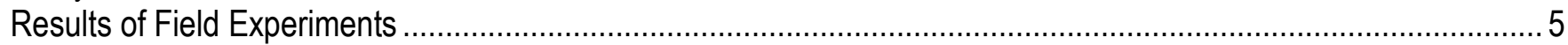

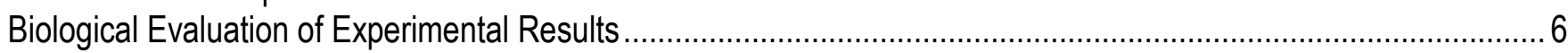

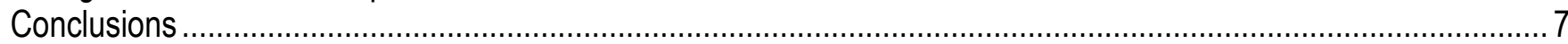

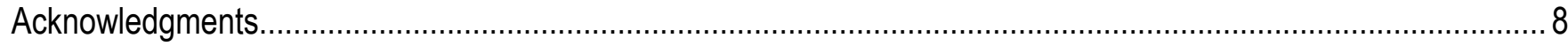

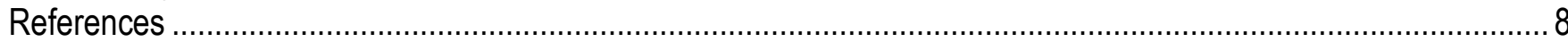

\section{Figures}

Figure 1. Photograph of the Herman Creek Screen, looking upstream, at the Oxbow Fish Hatchery, Cascade Locks, Oregon

Figure 2. Schematic of the modular screen apparatus used to evaluate the behavioral responses of juvenile salmonids encountering the leading edge of the Farmers Screen, 2010

Figure 3. Mean normal velocities (approach velocities corrected for the net open area of the screen) estimated for different sections of the Herman Creek screen relative to weir wall height and water depth, 2009

Figure 4. Distribution of the percent body surface area of large juvenile coho salmon injured when released over the Herman Creek screen (grey boxes) under different hydraulic conditions relative to control fish (white boxes).. 12 Figure 5. Distribution of the percent body surface area of small juvenile coho salmon injured when released over the Herman Creek screen (grey boxes) under different hydraulic conditions relative to control fish (white boxes).. 13

\section{Tables}

Table 1. Summary of hydraulic conditions at the Herman Creek screen and the numbers of two size groups of juvenile coho salmon used during injury assessments and delayed mortality tests

Table 2. General linear models describing the relation between hydraulic variables measured at the Herman Creek screen, 2009.

Table 3. Mean number of fish contacts with the screen, their relative depth of travel during passage, and their general orientation to the water flow during passage for large juvenile coho salmon experimentally released over the Herman Creek screen, 2009

Table 4. Mean number of fish contacts with the screen, their relative depth of travel during passage, and their general orientation to the water flow during passage for small juvenile coho salmon experimentally released over the Herman Creek screen, 2009

Table 5. Summary of hydraulic conditions at the modular screen, the number and species of fish used for testing, and the percentage of fish that successfully passed over the screen during consecutive five minute periods, 2010 


\section{Conversion Factors and Abbreviations and Symbols}

\section{Conversion Factors}

\begin{tabular}{lcl}
\hline \multicolumn{1}{c}{ Multiply } & By & \multicolumn{1}{c}{ To obtain } \\
\hline inch (in.) & Length & \\
inch (in.) & 2.54 & centimeter (cm) \\
& 25.4 & millimeter $(\mathrm{mm})$ \\
\hline foot per second (ft/s) & Flow rate & \\
\hline \multicolumn{1}{c}{ Multiply } & 0.3048 & meter per second $(\mathrm{m} / \mathrm{s})$ \\
\hline & By & To obtain \\
\hline centimeter $(\mathrm{cm})$ & Length & \\
millimeter $(\mathrm{mm})$ & 0.3937 & inch (in.) \\
meter $(\mathrm{m})$ & 0.03937 & inch (in.) \\
\hline & 3.281 & foot $(\mathrm{ft})$ \\
\hline centimeter per second $(\mathrm{cm} / \mathrm{s})$ & Flow rate & \\
cubic meter per second $\left(\mathrm{m}^{3} / \mathrm{s}\right)$ & 0.0328 & feet per second \\
\hline
\end{tabular}

\section{Abbreviations and Symbols}

\begin{tabular}{ll}
\hline \multicolumn{1}{c}{ Abbreviation and Symbol } & \multicolumn{1}{c}{ Meaning } \\
\hline AV & approach velocity \\
CRRL & Columbia River Research Laboratory \\
FID & Farmers Irrigation District \\
FL & fork length \\
h & hour \\
mg/L & milligram per liter \\
NMFS & National Marine Fisheries Service \\
NV & normal velocity \\
s & second \\
SV & sweeping velocity \\
UV & ultraviolet \\
Z & water depth \\
$<$ & less than \\
$>$ & greater than \\
\hline
\end{tabular}




\title{
Biological Evaluations of an Off-Stream Channel, Horizontal Flat-Plate Fish Screen-The Farmers Screen
}

\author{
By Matthew G. Mesa, Brien P. Rose, and Elizabeth S. Copeland
}

\begin{abstract}
Screens commonly are installed at water diversion sites to reduce entrainment of fish. Recently, the Farmers Irrigation District (Oregon) developed a flat-plate screen design (that is, the Farmers Screen) that operates passively and may offer reduced installation and operation costs to irrigators. To evaluate the performance of this type of screen (its biological effect on fish), we conducted two separate field experiments in consecutive years. First, in 2009, two size classes of juvenile coho salmon (Oncorhynchus kistuch) were released over a small working version of this screen at Herman Creek, Oregon. The screen was evaluated over a range of inflow [0.02-0.42 cubic meters per second $\left(\mathrm{m}^{3} / \mathrm{s}\right)$ ] and diversion flows $\left(0.02-0.34 \mathrm{~m}^{3} / \mathrm{s}\right)$ at different weir wall heights. The mean approach velocities ranged from 0 to 5 centimeters per second and mean sweeping velocities ranged from 36 to 178 centimeters per second. Water depths over the screen surface ranged from 1 to 25 centimeters and were directly related to weir wall height and inflow. Passage of juvenile coho salmon over the screen under various hydraulic conditions did not severely injure the fish or cause delayed mortality. Injury or mortality did not occur even though many fish contacted the screen surface during passage. No fish were observed becoming impinged on the screen surface. Second, in 2010, we constructed a modular screen apparatus that had 34 meters of wooden flume connected to a 3.5-meter long section of the Farmers Screen to determine whether fish would refuse to pass over the screen and swim back upstream after encountering the leading edge of the screen under various hydraulic conditions. For these tests, smolting coho salmon and steelhead trout (O. mykiss) were released at the upstream end of the flume and allowed to volitionally move downstream and pass over the screen. Overall, 81 and 91 percent of the fish moved downstream through the entire apparatus within 5 and 25 minutes from their release and only 1 of the 275 fish released swam back upstream after encountering the screen. Collectively, our results indicate that when operated within its design criteria, the Farmers Screen provided safe and efficient downstream passage of juvenile salmonids under various hydraulic conditions. However, we do not recommend operating the Herman Creek screen at inflows less than $0.14 \mathrm{~m}^{3} / \mathrm{s}$ because water depth can be quite shallow and the screen can completely dewater, particularly at low flows.
\end{abstract}




\section{Introduction}

Diversions from natural or manmade waterways are common in the United States and the water is used for many purposes. Many diversion structures are fitted with screens meant to prevent fishes and other aquatic life from becoming entrained in the diversion, injured, or killed. However, many thousands of water diversions remain unscreened. Some screening technology (for example, submersible traveling screens or rotary drum screens) and design criteria meant to protect fishes [National Marine Fisheries Service (NMFS), 2008] are relatively expensive and require frequent maintenance to operate properly (McMichael and others, 2004), which can limit the installation of screens in areas where screens are needed. Recently, the development of unique horizontal flat-plate fish screens offer designs that may be less expensive to install, offer simpler, more passive operation, and may have fewer detrimental effects on aquatic communities. Research on the hydraulic characteristics and biological effects of some flat-plate screens has been promising (Beyers and Bestgen, 2001; Frizell and Mefford, 2001; and Rose and others, 2008), but more work is needed to fully evaluate the performance of flat-plate screens. Evaluating different designs and sizes of horizontal flat-plate screens in the laboratory and in the field would allow further verification of screen performance, provide data for comparison with criteria for more traditional fish screens, and perhaps facilitate screen installation.

We evaluated the hydraulic and biological performance of a newly developed, off-stream channel horizontal flat-plate fish screen, also known as the Farmers Screen. These screens, designed over a 10-year period by personnel from the Farmers Irrigation District in Hood River, Oregon, have a higher rate of horizontal movement of water across the screen (sweeping velocity, SV) relative to the rate of movement of water through the screen (approach velocity, AV), good self-cleaning characteristics, the potential for reduced impingement, injury, and entrainment of fish, and may reduce installation and maintenance costs. The screens are manufactured in various sizes - a large version, designed to accommodate flows as large as $2.27 \mathrm{~m}^{3} / \mathrm{s}$, was subjected to hydraulic, debris-loading, and biological tests to evaluate injury and mortality to juvenile salmonids, including Chinook salmon (Oncorhynchus tshawytscha) and steelhead (O. mykiss). The test results showed that the large Farmers Screen did not cause injury or mortality to fish when operated in accordance with its design parameters (Craven Consulting Group, 2003). However, smaller versions of this screen have not been tested. Such evaluations would help to more fully evaluate the performance of these alternative technology screens.

The U.S. Geological Survey's Columbia River Research Laboratory (CRRL) conducted field experiments to assess the performance of this screen type during 2009 and 2010. The objectives of the study were to assess the hydraulic performance of the Farmers Screen and determine the effects of downstream passage of fish over the screen on their injury, delayed mortality, and behavior under various hydraulic conditions. This paper describes the study methods and results of those experiments. 


\section{Study Methods}

Screen hydraulics and biological performance (2009)—The screen evaluated for its hydraulic and biological performance was located at the Oxbow Fish Hatchery in Cascade Locks, Oregon (fig. 1). The screen is on a side-channel of Herman Creek, a tributary of the Columbia River, and is designed to divert $0.28 \mathrm{~m}^{3} / \mathrm{s}$ of water. The installation is similar to other Farmers Screens that have already been installed in the Pacific Northwest. For a complete description of this screen and of the Farmers Screen in general, see Farmers Conservation Alliance, 2006, http://www.farmerscreen.org/. For purposes of this report, we refer to this screen as the Herman Creek screen.

To assess the hydraulic performance of the Herman Creek screen, we adjusted the inflow entering the screen, measured the inflow and water depth $(Z)$, diversion discharge, and bypass discharge, and calculated mean $\mathrm{SV}, \mathrm{AV}$, and normal velocity $\mathrm{NV}$, which is the AV multiplied by the percentage of open area of the screen, or AV $\times 0.5)$ under different weir wall heights. After most of these hydraulic conditions were measured, we experimentally released fish over the screen. We evaluated the screen under four weir wall heights (that is, 4, 11, 13, and $20 \mathrm{~cm}$ ) and at inflows ranging from 0.02 to $0.42 \mathrm{~m}^{3} / \mathrm{s}$. We used multiple linear regression analysis to evaluate the influence of several continuous and discrete variables (for example, streamflow, weir wall height) on water depth over the screen, diversion discharge, and sweeping velocity. All coefficients are significant at the $P<0.05$ level unless noted.

To assess the biological performance of the Herman Creek screen, we experimentally released groups of juvenile coho salmon (O. kistuch) over the screen under various hydraulic conditions and quantified any injuries to the integument of the fish and documented short-term delayed mortality. Our test fish were from the Oxbow Hatchery and we evaluated two size groups, large [85-145 mm FL (fork length)] and small (54-78 mm FL)], in two separate sets of trials. Fish that passed over the screen (treatment fish) were released in groups of 10, at a distance of 1-2 $\mathrm{m}$ above the upper edge of the screen, and were recaptured in a net beneath the bypass outfall. Control fish were released into the bypass outfall and captured in a net and held for several minutes to simulate the time it took most treatment fish to pass over the screen. We used a fluorescein dye method described by Noga and Udomkusonsri (2002) to determine the extent of ulceration on the skin, eyes, and fins of each fish. After capture, both groups of fish were euthanized in a lethal dose of MS-222 $(200 \mathrm{mg} / \mathrm{L})$, rinsed in a freshwater bath for 1 minute, and then placed in a solution of fluorescein dye (fluorescein disodium salt at $20 \mathrm{mg} / \mathrm{L}$ ). After 6 minutes, fish were removed from the dye and rinsed in three separate freshwater baths over 3 minutes to remove excess dye. Images were taken of both sides of each fish in a dark box under ultraviolet (UV) light using a digital camera with a 200-mm macro lens. The UV lights were placed at $45^{\circ}$ angles to the side of the fish and a yellow barrier filter was used to eliminate the blue autofluorescence. Images were imported into Adobe (C) Photoshop CS3 and the body surface area and area of fluorescence was measured on each side of a fish. The percentage of body surface area of a fish that was injured was derived by dividing the total area of fluorescence by the total body surface area. This included the two sides and most, but not all, of the dorsal and ventral surfaces of the fish. For each release group, we compared the percentage of body surface area of the fish that was injured for control and treatment fish using two-sample, Mann-Whitney $U$ tests. We were interested in whether the levels of injury in treatment fish were significantly different than those of control fish. The level of significance was set at $P<0.05$. 
To assess delayed mortality after passage, additional fish were released in the same manner as described above but were transported to holding tanks after being collected in the bypass outfall. Fish were monitored for 24-48 $\mathrm{h}$ after passage and handling and the number of fish that died was compared between treatment and control groups. Mortality tests were conducted for most, but not all, of the same hydraulic conditions as injury tests.

To document the behavior of fish passing over the screen, treatment fish were videotaped using three underwater cameras mounted to one edge of the screen. The system was not designed to cover the entire screen area, and each camera provided only a partial, upstream view of the screen. Video files were reviewed in slow motion, and the approximate number of times fish contacted the screen, their orientation to the current during passage, and their general depth of passage were recorded. Control fish were not videotaped.

Behavioral responses of fish encountering the leading edge of a screen (2010)-To evaluate whether fish would refuse to pass over the screen after encountering the leading edge (a question we did not answer in 2009), we constructed a modular screen apparatus that had $34 \mathrm{~m}$ of wooden flume (46-cm wide by 36-cm deep) connected to a 3.1-m (long section of the Farmers Screen (fig. 2). The purpose of the long flume was to provide fish with plenty of distance between their release point (at the upstream end of the flume) and the upstream edge of the screen so the fish could orient themselves and move downstream somewhat naturally. The flume received water from the outflow of the Herman Creek Screen and was designed so that water velocities were slower in the upstream one-half of the flume than in the downstream one-half. We installed a trap on the downstream end of the screen to capture the fish.

We used yearling coho salmon (113-161 mm FL) from the Oxbow State Fish Hatchery (Oregon) and Skamania-stock steelhead (134-260 mm FL) from the Bonneville Fish Hatchery (Oregon) for tests. We used fish presumably undergoing the process of smoltification to maximize the probability that the fish would have a strong desire to migrate downstream. All the test fish were large and silvery with faint or non-existent parr marks. These fish should have had a relatively strong swimming ability (compared to smaller fish) and thus would be most likely to reject the screen if conditions posed a behavioral obstacle. Normally, these fish would have been released from the hatcheries during midApril to early May. Prior to testing, all fish were held in large tanks at the Oxbow State Fish Hatchery and water temperatures were monitored daily.

On the day of testing, we first established the hydraulic conditions for the test, including inflow volume, water depth, AV, and SV over the screen, and water velocity and depths at several locations throughout the flume. Our intent was to test fish under various hydraulic conditions over the screen. We then removed 10 fish from their holding tank, placed them in a 19-L bucket with water, transported them from the hatchery to the test facility (about $2 \mathrm{~km}$ ), and gently released them at the upstream end of the flume. Fish were allowed 20 minutes to volitionally migrate down the flume and pass over the screen. After 20 minutes, we gently prodded any fish that remained in the upper $3 \mathrm{~m}$ of the flume until the fish moved downstream. We conducted three to four releases of about 10 fish each, for a total release of 20-40 fish for each species under the various hydraulic conditions.

An observer was stationed on an elevated platform slightly upstream of the fish screen to record the behavior and passage timing of fish as they approached the screen. For each of five consecutive 5minute periods, we recorded the number of fish that encountered the screen and whether the fish passed over the screen or refused to (that is, the fish turned and swam back upstream). For our analysis, we pooled data from the release groups for each species and hydraulic condition and determined the proportion of fish that passed over or rejected the screen for each time period. We also tallied data from each time period and determined the proportion of fish that passed over the screen within 25 minutes of their release. 


\section{Results of Field Experiments}

Screen hydraulics and biological performance (2009)_Hydraulic conditions measured at the Herman Creek screen and the numbers of coho salmon released for injury and delayed mortality assessments are summarized in table 1. Diversion discharges (the volume of water collected from the screen and sent to the hatchery) comprised from 65 to 100 percent of the inflow rates. Mean AVs estimated for the entire screen ranged from 0 to $5 \mathrm{~cm} / \mathrm{s}$ and for individual sections of the screen, mean AVs never exceeded $6 \mathrm{~cm} / \mathrm{s}$. Mean NVs ranged from 0 to $10 \mathrm{~cm} / \mathrm{s}$ and varied along the length of the screen (fig. 3). Mean SVs ranged from 36 to $178 \mathrm{~cm} / \mathrm{s}$ and generally were faster at the upstream edge and slower at the downstream edge of the screening panels. Mean SVs usually were at least 32 times higher than AVs for all conditions tested. The mean $\mathrm{Z}$ ranged from 1 to $25 \mathrm{~cm}$ and generally was deeper at the upstream end of the screen than at the downstream end. Mean depths were directly related to weir wall height and inflow and were inversely related to diversion discharge $\left(R^{2}=0.84\right.$; table 2$)$, mean SVs were inversely related to weir wall height and diversion discharge and were directly related to inflow $\left(R^{2}=0.81\right.$; table 2$)$, and diversion discharge was related to several variables $\left(R^{2}=0.99\right.$; table 2$)$. "Hot spots" or localized areas of high AV with spiraling flow were not observed during any of our tests.

Overall, the injury rates of fish after passage over the Herman Creek screen were low, and severe injuries to the skin, eyes, and fins of both size cohorts were not observed. For large fish, the mean percentage of body surface area that was injured varied by release group and ranged from about 0.5 to 2.5 percent (fig. 4). The mean percentage of body surface area that was injured in treatment fish was significantly different than that of control fish for all test conditions (Mann-Whitney $U$ tests, $P<0.05$; fig. 4), but the magnitude of these differences was small $(<1$ percent). For small fish, the mean percentage of body surface area that was injured ranged from about 0.4 to 3.0 percent (fig. 5). The mean percentage of body surface area that was injured in treatment fish was significantly different than that in control fish for three test conditions (fig. 5), but again, the magnitude of this difference was small $(<1$ percent). One small fish, shown as an outlier in figure 5 with about 60 percent of its body surface area injured, probably was injured by something other than passage over the screen. For delayed mortality after passage, we tested 849 fish in total and none died within $24-48 \mathrm{~h}$ of passage or handling and only one control fish died.

The results of our video analysis revealed that for large fish, the mean number of times fish contacted the screen surface ranged from 0.15 to 0.72 per fish observed (table 3 ). During passage, most fish remained low in the water column near the screen surface (table 3). Fish were oriented either upstream or downstream during passage, with no clear relation to the hydraulic conditions (table 3 ). For small fish, the mean number of times fish contacted the screen surface ranged from 0.26 to 0.62 per fish observed (table 4). Again, most fish remained low in the water column and near the screen surface during passage. Most fish were oriented upstream during passage.

Behavioral responses of fish encountering the leading edge of a screen (2010)-To evaluate the behavioral responses of juvenile salmonids approaching and passing over the screen, we released a total of 173 coho salmon and 102 steelhead trout in the modular screen apparatus under various hydraulic conditions (table 5). In general, the hydraulic conditions in the modular screen system were similar to those recorded in the Herman Creek screen. For example, mean AVs estimated for the entire screen ranged from 1 to $3 \mathrm{~cm} / \mathrm{s}$ or 2 to $6 \mathrm{~cm} / \mathrm{s}$ after correcting for net open area (50 percent) and $\mathrm{Z}$ ranged from 15 to $25 \mathrm{~cm}$. Mean SVs ranged from 102 to $150 \mathrm{~cm} / \mathrm{s}$ and were at least 32 times higher than AVs for all tests. In the flume, mean water velocities ranged from 60 to $79 \mathrm{~cm} / \mathrm{s}$ in the upstream one-half of the flume and from 85 to $104 \mathrm{~cm} / \mathrm{s}$ in the downstream one-half of the flume. Mean values of $Z$ in the flume ranged from 23 to $31 \mathrm{~cm}$. For coho salmon, from 75 to 95 percent of the fish approached and passed over the screen within 5 minutes of their release, depending on hydraulic conditions (table 5). Within 20 
minutes, the percentages of fish that quickly passed over the screen increased to $82-98$ percent. After 20 minutes, 12 fish remained upstream in the flume and were gently prodded to move downstream; all these fish passed over the screen without hesitation. For steelhead trout, from 47 to 90 percent of the fish approached and passed over the screen within 5 minutes of their release, depending on hydraulic conditions (table 5). Within 20 minutes, the percentages of fish that quickly passed over the screen increased to 79-95 percent. After 20 minutes, 11 fish (11 percent) were coerced downstream of the upper $3 \mathrm{~m}$ of the flume and one fish turned and swam back upstream after it encountered the screen. However, this fish returned to the screen within 10 minutes and successfully passed. Overall, 99.6 percent of the fish we observed passed over the screen without hesitation or delay.

\section{Biological Evaluation of Experimental Results}

The results of our experiments in 2009 indicate that passage of juvenile coho salmon over the Herman Creek screen under various hydraulic conditions did not severely injure the fish, cause delayed mortality, or delay fish migration. These results occurred even though most fish passed over the screen near the screen surface, many contacted the screen during passage, and fish were oriented to the current in various directions. However, we did not observe fish becoming impinged on the screen surface (that is, $>1$ second contact with the screen). The screen showed good self-cleaning performance and never had problems with debris loading. Our results are similar to those of Rose and others (2008), who also reported minimal injuries and low mortality of rainbow trout after passage over backwatered and inverted-weir horizontal flat-plate screens in Oregon. Other studies evaluated various designs of vertically oriented screens and reported results similar to ours (Danley and others, 2002; Zydlewski and Johnson, 2002).

The injuries observed in our fish — both treatment and control groups — were minor and indicate that fish had some trauma to the integument prior to testing and that our holding and handling procedures probably caused more trauma. The fluorescein dye method was effective for detecting injuries to the integument of fish and revealed that all fish had some level of injury after testing. As stated previously, however, all injuries were minor and any differences in mean injury rates between treatment and control groups were small, which makes it difficult to ascribe any biological significance to the injuries we observed. Furthermore, and perhaps more importantly, none of our test results would have exceeded the performance standards for safe passage of fish over conventional screen systems as established by NMFS. For example, performance standards set by NMFS include less than 0.5 percent mortality and 2 percent injury rate (that is, the percentage of a sample that is injured) for salmonid smolts, and that at least 90 percent of salmonids that encounter a screened water diversion are bypassed within 24 h (Bryan Nordlund, National Marine Fisheries Service, written commun., 2010). The agency defines injury as visual trauma (including but not limited to hemorrhaging, open wounds without fungus growth, gill damage, bruising greater than $0.5 \mathrm{~cm}$ in diameter), loss of equilibrium, or greater than 20 percent descaling on one side (Bryan Nordlund, National Marine Fisheries Service, written commun., 2009). Because none of our fish showed such injuries, mortality was less than 0.5 percent, and most fish traveled over the screen without hesitation or delay, the Herman Creek screen would surpass these NMFS standards. Although the performance standards discussed here are for other types of screens, the standards do indicate that screens like the one at Herman Creek probably would, at a minimum, meet federal regulatory standards.

The ability of the Herman Creek screen to safely and efficiently pass fish at water depths ranging from 7 to $25 \mathrm{~cm}$ was largely due to achieving a high ratio of SV to AV (30:1-60:1) under various diversion conditions. These ratios were substantially higher than the SV recommendations established by NMFS for horizontal screens, which only suggest that downstream SVs be higher than AVs for the 
entire length of the screen (National Marine Fisheries Service, 2008). The combination of high SVs and low AVs facilitated quick downstream fish passage and eliminated impingements; results are similar to Beyers and Bestgen (2001). Because most fish passed over the screen near the screen surfaceregardless of water depth - indicates that the $30 \mathrm{~cm}$ water depth recommendation established for horizontal screens (National Marine Fisheries Service, 2008) could be relaxed for smaller screens like the one at Herman Creek. Although fish safely passed over the screen at a depth of only $7 \mathrm{~cm}$, the number of screen contacts per fish increased at this shallow depth for large, but not small, fish. Even though the screen contact rate was not related to the extent or severity of injuries, operating the screen at water depths near $7 \mathrm{~cm}$ seems too shallow, particularly under high-flow conditions. Thus, although our results suggest that the Herman Creek screen can be operated effectively at water depths less than 30 $\mathrm{cm}$, we cannot unequivocally recommend a single, specific minimum depth for this screen. Rather, a range of minimum depths, perhaps from 15 to $20 \mathrm{~cm}$, probably would provide safe passage of fish under most circumstances.

Despite the advantages of the Herman Creek screen for protecting fish populations, there are some things to consider when interpreting our results. First, we were unable to evaluate all possible hydraulic conditions on screen performance, fish injury, and mortality. Although we believe our evaluations were realistic because they encompassed typical diversion conditions, there may be other flow conditions we missed that are relevant to fish passage and safety. Second, only two species of fish were tested for the screen evaluations and our results may not be applicable to other species. The fishes used in our experiments probably were good surrogates for other salmonids of similar size.

Extrapolation of our results to other fishes, such as juvenile lampreys or endangered suckers in the Klamath Basin, seems inappropriate and would require further testing. Next, our video analyses were not rigorous and our camera installation was meant to provide qualitative information on the behavior of fish as they passed over the screen. Even though we used three cameras, we had limited fields of view and it was often difficult to see because of water turbidity, sunlight, or other factors. Although we are confident that the data we did collect were representative of fish behavior during passage, more detailed analyses will require further work. Finally, we evaluated only the effects of downstream passage on juvenile fish. Further testing would be required to assess the effects of this screen type on fish migrating upstream across the screen surface.

The purpose of our testing in 2010 was to determine whether fish would reject or refuse to pass over the screen after encountering its leading edge - a notion that was a concern to fishery managers and something we did not evaluate in 2009. The concern was related to the changing hydraulic conditions at the flume-screen interface and whether fish would sense this change, turn around, and refuse to pass. Extended delays in passage over the screen could lead to excessive energy use in fish and violation of the NMFS standard that fish must be bypassed within $24 \mathrm{~h}$. Our results, however, clearly indicate that the flume-screen interface was not an obstacle to passage for fish moving volitionally downstream, because high percentages of fish passed within 20 minutes. Even the small number of fish we had to manually coerce to move downstream readily passed over the flume-screen interface. We cannot state whether all fish encountering and passing through small versions of the Farmers Screen would be bypassed within $24 \mathrm{~h}$ because none of our tests were designed to answer this question. However, we think the possibility of fish not passing over these screens within $24 \mathrm{~h}$ would be remote.

\section{Conclusions}

When operated within its design criteria-diversion flows of about $0.28 \mathrm{~m}^{3} / \mathrm{s}$ - the Herman Creek screen provided safe and effective downstream passage of juvenile coho salmon under various hydraulic conditions. We do not recommend operating the Herman Creek screen at inflows less than 
about $0.14 \mathrm{~m}^{3} / \mathrm{s}$ because water depth can be quite shallow due in part to a weir wall that was not sealed and the screen can completely dewater, particularly at low flows. If the screen is operated at inflows less than $0.14 \mathrm{~m}^{3} / \mathrm{s}$, caution must be used to avoid diverting an excessive amount of water, which can lead to shallow depths, insufficient bypass flow, and perhaps screen dewatering. Finally, we do not know the fate of fish that pass over the screen, enter the bypass channel, and are diverted back to the Columbia River. It is possible that passage through these areas is a stressful and disorienting event for fish, which could make them vulnerable to hazards that exist downstream, such as predation by fish or birds. This idea is not unique to the Herman Creek screen, but is relevant for many types of diversions and obstacles fish may encounter in the wild. Further research would be necessary to address this issue.

\section{Acknowledgments}

We thank Les Perkins, Julie Davies O’Shea, and Daniel Kleinsmith of The Farmers Conservation Alliance for financial and technical support; Jerry Bryan for his expertise and advice on the Farmers Screen; Duane Banks and his staff from the Oxbow Fish Hatchery for use of their facility and technical assistance; Bryan Nordlund, Michelle Day, and Larry Swenson of NMFS for early discussions and advice on our study; and staff from the Columbia River Research Laboratory for their assistance in the field.

\section{References Cited}

Beyers, D.W., and Bestgen, K.R., 2001, Bull trout performance in a horizontal flat plate screen: Final report to the Bureau of Reclamation, Water Resources Research Group, Denver, Colorado.

Craven Consulting Group, 2003, July 28, 2003 Memorandum and Draft Data Report_Evaluation of Overshot Horizontal Flat Plate Fish Screen: Farmers Canal, Hood River, Oregon. Prepared by Craven Consulting Group/Farmers Irrigation District.

Danley, M.L., Mayr, S.D., Young, P.S., and Cech, J.J., Jr., 2002, Swimming performance and physiological stress responses of split tail exposed to a fish screen: North American Journal of Fisheries Management, v. 22, p. 1241-1249.

Farmers Conservation Alliance, 2006, Resource solutions for rural communities: accessed November 12, 2010, at http://www.farmerscreen.org/.

Frizell, K., and Mefford, B., 2001, Hydraulic performance of a horizontal flat plate screen: Final report to the Bureau of Reclamation, Water Resources Research Group, Denver, Colorado.

McMichael, G.A., Vucelick, J.A., Albernathy, C.S., and Neitzel D.A., 2004, Comparing fish screen performance to physical design criteria: Fisheries, v. 29, chap. 7, p. 10-16.

National Marine Fisheries Service (NMFS), 2008, Anadromous salmonid passage facility design: NMFS, Northwest Region, Portland, Oregon.

Noga, E.J., and Udomkusonsri, P., 2002, Fluorescein: a rapid, sensitive, nonlethal method for detecting skin ulceration in fish: Veterinary Pathology, v. 39, p. 726-731.

Rose, B.P., Mesa M.G., and Zydlewski G.B., 2008, Field-base evaluations of horizontal flat plate fish screens: North American Journal of Fisheries Management, v. 28, p. 1702-1713.

Zydlewski, G.B., and Johnson, J.R., 2002, Response of bull trout fry to four types of water diversion screens: North American Journal of Fisheries Management, v. 22, p. 1276-1282. 


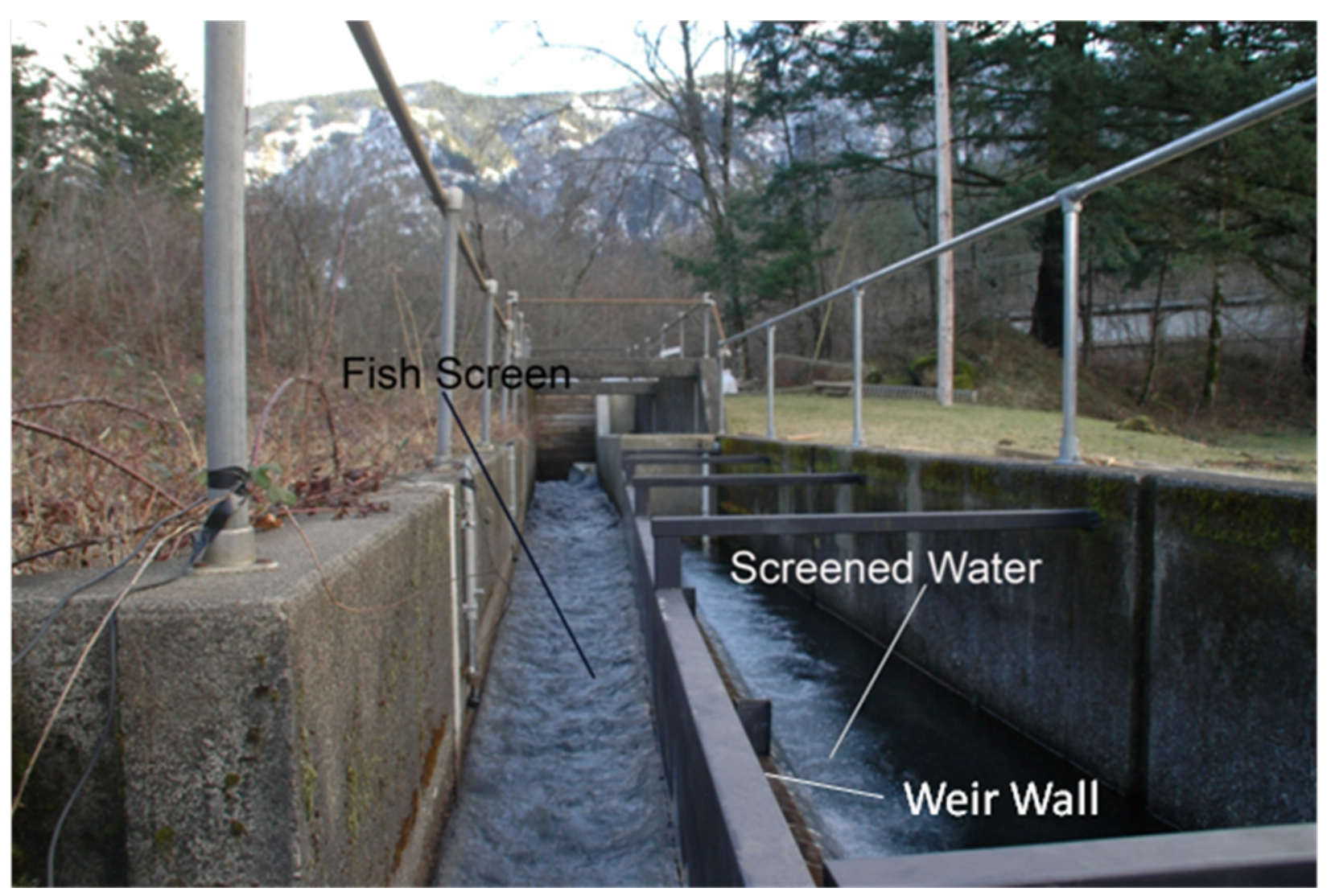

Figure 1. Photograph of the Herman Creek Screen, looking upstream, at the Oxbow Fish Hatchery, Cascade Locks, Oregon. Photograph taken by Brien P. Rose. 


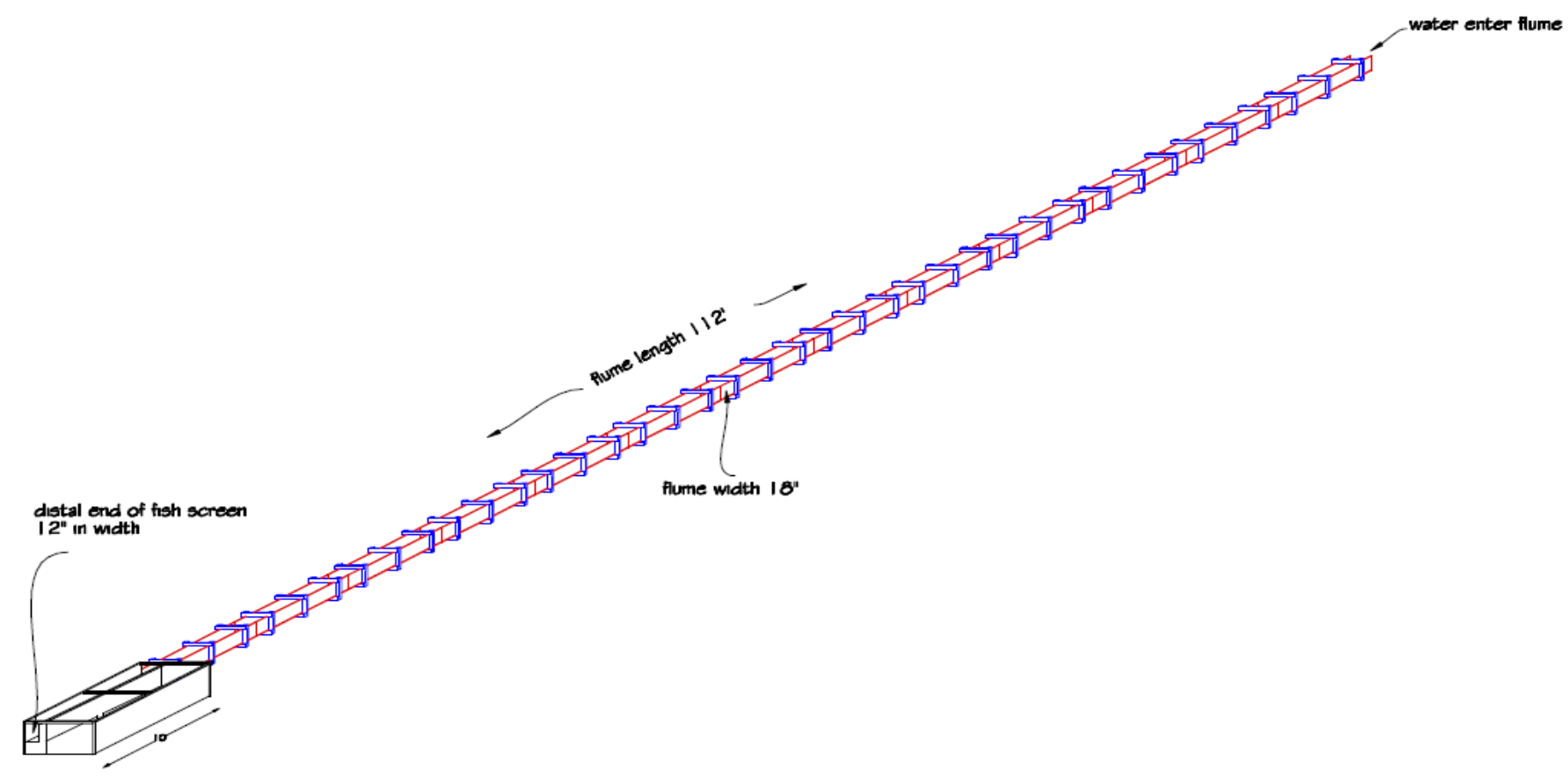

Figure 2. Schematic of the modular screen apparatus used to evaluate the behavioral responses of juvenile salmonids encountering the leading edge of the Farmers Screen, 2010. The modular screen apparatus consisted of a 34 m of wooden flume connected to a 3.1-m long section of the Farmers Screen. 


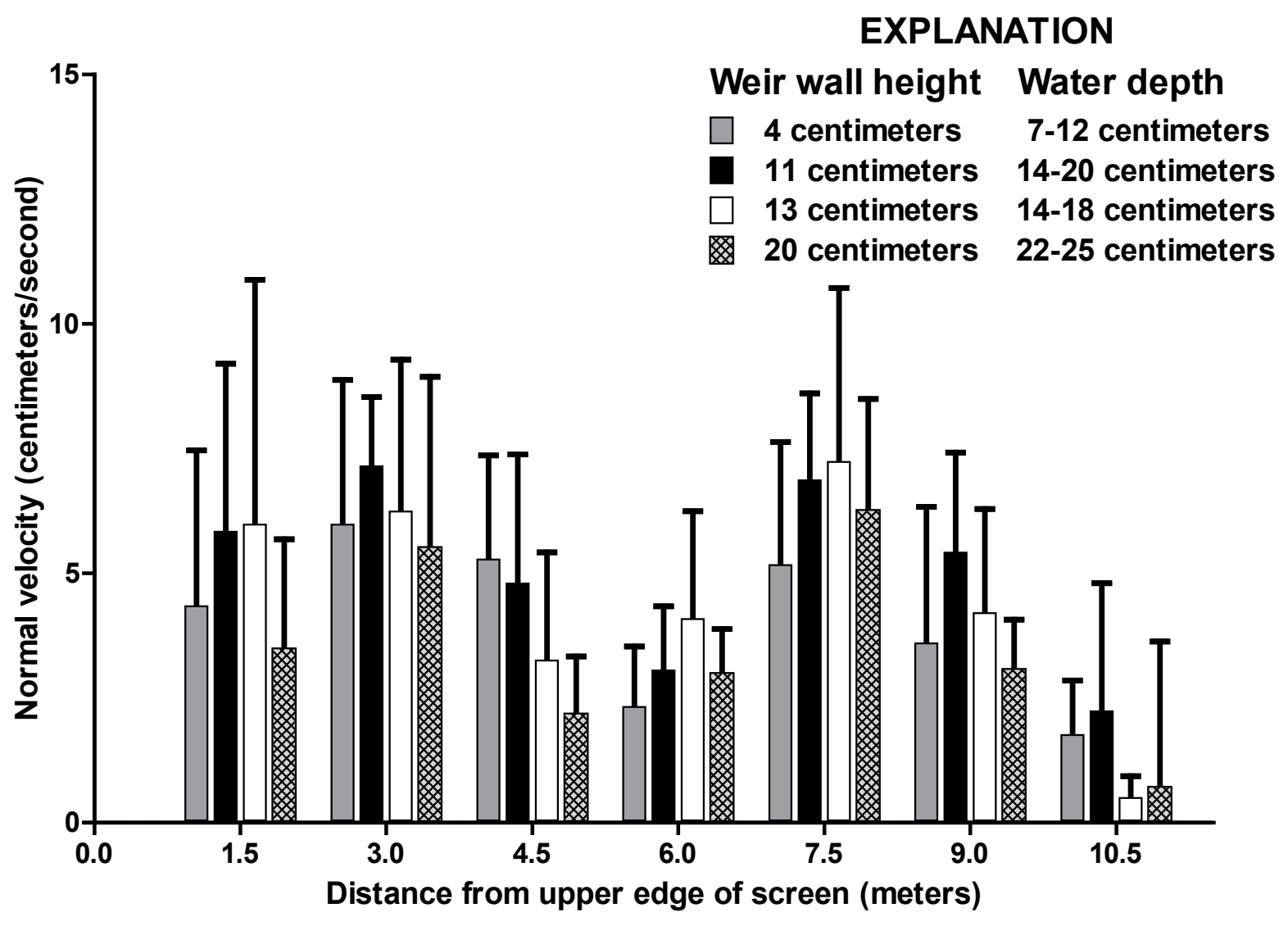

Figure 3. Mean normal velocities (approach velocities corrected for the net open area of the screen) estimated for different sections of the Herman Creek screen relative to weir wall height and water depth, 2009. The whiskers represent the standard deviations of the estimates. 


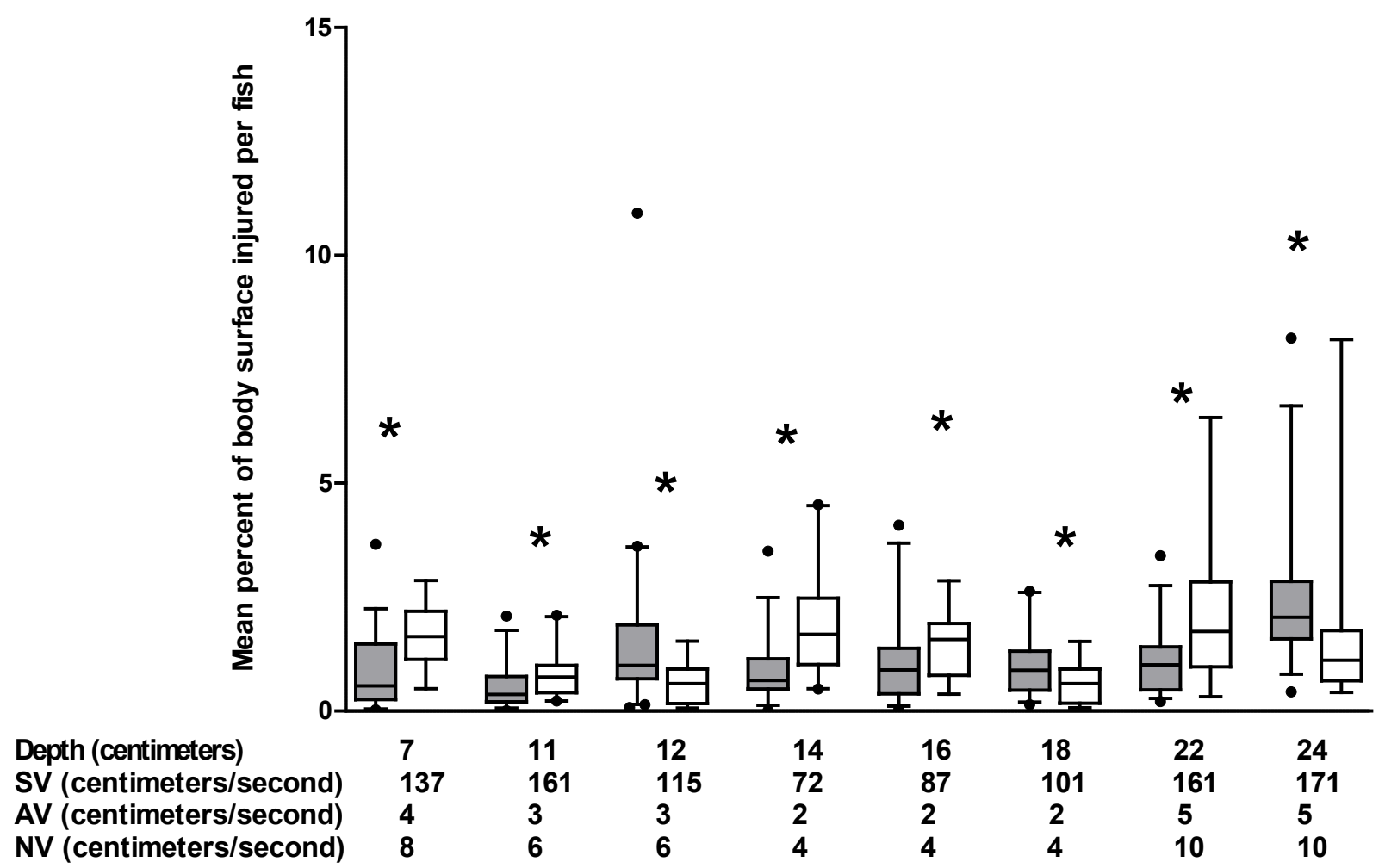

Figure 4. Distribution of the percentage of body surface area of large juvenile coho salmon injured when released over the Herman Creek screen (grey boxes) under various hydraulic conditions relative to control fish (white boxes). The upper and lower boundaries of the box represent the $25^{\text {th }}$ and $75^{\text {th }}$ quartiles, the line inside the box is the mean, the whiskers represent the 5- and 95-percent confidence intervals, and outliers are shown by solid points. The X-axis shows the water depth over the screen, the mean sweeping velocity (SV), the approach velocity $(\mathrm{AV})$, and the normal velocity (NV) during each test. Asterisks denote a significant difference between medians within a group (Mann Whitney $U$ test, $P<0.05$ ). 


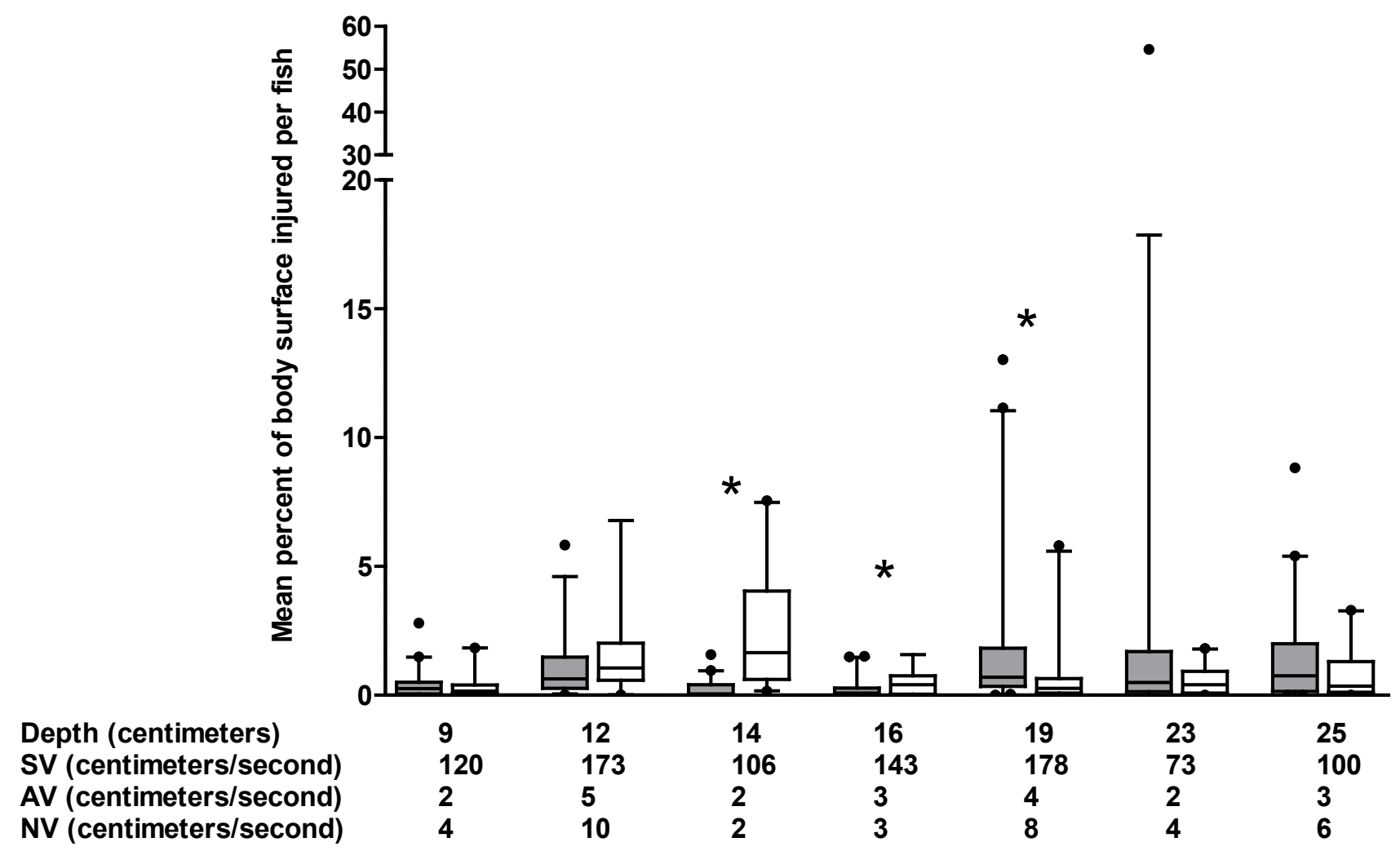

Figure 5. Distribution of the percentage of body surface area of small juvenile coho salmon injured when released over the Herman Creek screen (grey boxes) under different hydraulic conditions relative to control fish (white boxes). The upper and lower boundaries of the box represent the $25^{\text {th }}$ and $75^{\text {th }}$ quartiles, the line inside the box is the mean, the whiskers represent the 5- and 95-percent confidence intervals, and outliers are shown by solid points. The X-axis shows the water depth over the screen, the mean sweeping velocity (SV), the approach velocity $(\mathrm{AV})$, and the normal velocity (NV) during each trial. Asterisks denote a significant difference between medians within a group (Mann Whitney $U$ test, $P<0.05$ ). 
Table 1. Summary of hydraulic conditions at the Herman Creek screen and the numbers of two size groups of juvenile coho salmon used during injury and delayed mortality assessments.

[Trials were conducted on different days during February through May 2009. Q, discharge; SV, sweeping velocity; AV, approach velocity; Z, water depth over the screen; T, treatment fish; C, control fish. SD, standard deviation; cm, centimeters; $\mathrm{cm} / \mathrm{s}$, centimeters per second; $\mathrm{m}^{3} / \mathrm{s}$, cubic meters per second. Values in parentheses are data for delayed mortality tests. na, not available]

\begin{tabular}{|c|c|c|c|c|c|c|c|c|c|}
\hline \multirow{2}{*}{$\begin{array}{c}\text { Inflow } Q \\
\left(\mathrm{~m}^{3} / \mathrm{s}\right)\end{array}$} & \multirow{2}{*}{$\begin{array}{c}\text { Diversion Q } \\
\quad\left(\mathrm{m}^{3} / \mathbf{s}\right)\end{array}$} & \multirow{2}{*}{$\begin{array}{c}\text { Bypass } Q \\
\left(\mathrm{~m}^{3} / \mathrm{s}\right)\end{array}$} & \multirow{2}{*}{$\begin{array}{c}\text { SV } \\
(\mathrm{cm} / \mathrm{s} ; \\
\text { mean } \\
[\mathrm{SD}])\end{array}$} & \multirow{2}{*}{$\begin{array}{c}\mathrm{AV} \\
(\mathrm{cm} / \mathrm{s})\end{array}$} & \multirow{2}{*}{$\begin{array}{c}Z \\
(\mathrm{~cm} ; \\
\text { mean } \\
[S D])\end{array}$} & \multicolumn{2}{|c|}{ Large fish } & \multicolumn{2}{|c|}{ Small fish } \\
\hline & & & & & & $\mathrm{T}$ & C & $T$ & C \\
\hline \multicolumn{10}{|c|}{ 4-cm weir wall height } \\
\hline 0.10 & 0.10 & 0.00 & $67(34)$ & 1 & $7(1)$ & & & & \\
\hline 0.14 & 0.13 & 0.01 & $87(41)$ & 2 & $7(1)$ & 37 & 17 & & \\
\hline 0.15 & 0.14 & 0.01 & $120(50)$ & 2 & $9(1)$ & & & $40(44)$ & $19(15)$ \\
\hline 0.26 & 0.23 & 0.03 & $166(52)$ & 3 & $12(1)$ & & & & \\
\hline 0.27 & 0.25 & 0.02 & $137(49)$ & 4 & $11(3)$ & $38(65)$ & 20 & & \\
\hline 0.29 & 0.26 & 0.02 & $138(73)$ & 4 & $10(1)$ & & & & \\
\hline 0.31 & 0.28 & 0.02 & $130(46)$ & 4 & $12(2)$ & & & & \\
\hline 0.34 & 0.31 & 0.03 & $173(45)$ & 5 & $12(1)$ & & & $39(51)$ & $19(17)$ \\
\hline 0.36 & 0.33 & 0.03 & $171(41)$ & 5 & $12(1)$ & $41(60)$ & $15(30)$ & & \\
\hline \multicolumn{10}{|c|}{ 11-cm weir wall height } \\
\hline 0.14 & 0.11 & 0.03 & $101(30)$ & 2 & $14(1)$ & 39 & 20 & & \\
\hline 0.15 & 0.12 & 0.03 & $106(30)$ & 2 & $14(1)$ & & & $40(45)$ & $20(18)$ \\
\hline 0.29 & 0.23 & 0.05 & $161(23)$ & 3 & $16(2)$ & 40 & 20 & & \\
\hline 0.29 & 0.23 & 0.06 & $143(30)$ & 3 & $16(1)$ & & & $40(45)$ & $14(15)$ \\
\hline 0.34 & 0.26 & 0.08 & $178(32)$ & 4 & $19(1)$ & & & $41(36)$ & $20(15)$ \\
\hline 0.42 & 0.34 & 0.07 & $161(30)$ & 5 & $18(1)$ & $38(61)$ & $15(42)$ & & \\
\hline \multicolumn{10}{|c|}{ 13-cm weir wall height } \\
\hline 0.10 & 0.09 & 0.02 & $61(20)$ & 1 & $14(0)$ & & & & \\
\hline 0.20 & 0.13 & 0.07 & $170(36)$ & 2 & $16(2)$ & & & & \\
\hline 0.31 & 0.24 & 0.06 & $127(25)$ & 4 & $20(1)$ & & & & \\
\hline \multicolumn{10}{|c|}{ 20-cm weir wall height } \\
\hline 0.02 & 0.02 & 0.00 & na & 0 & $1(1)$ & & & & \\
\hline 0.04 & 0.03 & 0.01 & $36(15)$ & 0 & $8(0)$ & & & & \\
\hline 0.15 & 0.10 & 0.05 & $72(12)$ & 2 & $22(1)$ & 38 & 14 & & \\
\hline 0.15 & 0.10 & 0.05 & $73(12)$ & 2 & $23(0)$ & & & $36(44)$ & $20(15)$ \\
\hline 0.27 & 0.20 & 0.07 & $100(15)$ & 3 & $25(1)$ & & & $35(45)$ & $20(15)$ \\
\hline 0.28 & 0.22 & 0.06 & $115(17)$ & 3 & $24(1)$ & $39(60)$ & $15(52)$ & & \\
\hline 0.29 & 0.21 & 0.08 & $101(25)$ & 3 & $25(1)$ & & & & \\
\hline
\end{tabular}


Table 2. General linear models describing relation between hydraulic variables measured at the Herman Creek screen, 2009.

[All coefficients are significant $(\mathrm{P}<0.05)$ unless noted. SV, sweeping velocity; Z, depth of water over screen; SQ, inflow discharge; DQ, diversion discharge; WW, weir wall height; SEE, standard error of estimate; $\mathrm{cm}$, centimeters; $\mathrm{m}^{3} / \mathrm{s}$, cubic meters per second]

\begin{tabular}{ll}
\hline \multicolumn{1}{c}{ Dependent variable } & Equation \\
\hline Depth & $\mathrm{Z}=2.592^{1}+0.572(\mathrm{WW})+89.673(\mathrm{SQ})-75.712(\mathrm{DQ})$ \\
& $N=24, R^{2}=0.84, \mathrm{SEE}=2.27$ \\
Diversion discharge & $\mathrm{WQ}=0.056-0.003(\mathrm{WW})+0.902(\mathrm{SQ})+0.000(\mathrm{SV})$ \\
& $N=24, R^{2}=0.99, \mathrm{SEE}=0.01$ \\
Sweeping velocity & $\mathrm{SV}=105.007-4.863(\mathrm{WW})+1,166.178(\mathrm{SQ})-1,063.394(\mathrm{DQ})$ \\
& $N=24 R^{2}=0.81, \mathrm{SEE}=17.82$ \\
\hline
\end{tabular}


Table 3. Mean number of fish contacts with the screen, their relative depth of travel during passage, and their general orientation to the water flow during passage for large juvenile coho salmon experimentally released over the Herman Creek screen, 2009.

[AV, approach velocity; SV, sweeping velocity; SD, standard deviation; $\mathrm{cm}$, centimeter; cm/s, centimeter per second]

\begin{tabular}{lcccccccccc}
\hline Date & $\begin{array}{c}\text { Water } \\
\text { depth } \\
\text { (cm; } \\
\text { mean } \\
\text { [SD])) }\end{array}$ & $\begin{array}{c}\text { AV } \\
\text { (cm/s) }\end{array}$ & $\begin{array}{c}\text { SV (cm/s; } \\
\text { mean } \\
\text { [SD]) }\end{array}$ & $\begin{array}{c}\text { Mean (SD) } \\
\text { number of } \\
\text { screen } \\
\text { contacts per } \\
\text { fish }\end{array}$ & $\begin{array}{c}\text { Depth in water column } \\
\text { (percentage of } \\
\text { observed) }\end{array}$ & \multicolumn{2}{c}{$\begin{array}{c}\text { Orientation } \\
\text { (percentage of observed) }\end{array}$} \\
\hline $2 / 27$ & 7 & 2 & $87(41)$ & $0.72(0.58)$ & 69 & 25 & 6 & 44 & 56 & 0 \\
$2 / 17$ & 11 & 4 & $137(49)$ & $0.45(0.23)$ & 41 & 54 & 5 & 36 & 60 & 4 \\
$3 / 4$ & 12 & 5 & $171(41)$ & $0.47(0.24)$ & 53 & 35 & 12 & 55 & 45 & 0 \\
$3 / 2$ & 14 & 2 & $101(30)$ & $0.26(0.18)$ & 58 & 35 & 6 & 35 & 65 & 0 \\
$2 / 18$ & 16 & 3 & $161(23)$ & $0.41(0.23)$ & 44 & 43 & 13 & 58 & 42 & 0 \\
$3 / 3$ & 18 & 5 & $161(30)$ & $0.15(0.18)$ & 66 & 28 & 5 & 33 & 67 & 0 \\
$2 / 24$ & 22 & 2 & $72(12)$ & $0.41(0.34)$ & 69 & 25 & 5 & 53 & 47 & 0 \\
$2 / 19$ & 24 & 3 & $115(17)$ & $0.41(0.33)$ & 60 & 32 & 8 & 46 & 54 & 0 \\
\hline
\end{tabular}


Table 4. Mean number of fish contacts with the screen, their relative depth of travel during passage, and their general orientation to the water flow during passage for small juvenile coho salmon experimentally released over the Herman Creek screen, 2009.

[AV, approach velocity; SV, sweeping velocity; SD, standard deviation; $\mathrm{cm}$, centimeter; cm/s, centimeter per second]

\begin{tabular}{|c|c|c|c|c|c|c|c|c|c|c|}
\hline \multirow[t]{2}{*}{ Date } & \multirow{2}{*}{$\begin{array}{l}\text { Water } \\
\text { depth } \\
\text { (cm; } \\
\text { mean } \\
\text { [SD]) }\end{array}$} & \multirow{2}{*}{$\begin{array}{c}A V \\
(\mathrm{~cm} / \mathrm{s})\end{array}$} & \multirow{2}{*}{$\begin{array}{l}S V(\mathbf{c m} / \mathbf{s} ; \\
\text { mean } \\
[S D])\end{array}$} & \multirow{2}{*}{$\begin{array}{l}\text { Mean (SD) } \\
\text { number of } \\
\text { contact per } \\
\text { fish }\end{array}$} & \multicolumn{3}{|c|}{$\begin{array}{l}\text { Depth in water column } \\
\text { (percentage of } \\
\text { observed) }\end{array}$} & \multicolumn{3}{|c|}{$\begin{array}{c}\text { Orientation } \\
\text { (percentage of observed) }\end{array}$} \\
\hline & & & & & low & mid & high & $\begin{array}{c}\text { up } \\
\text { stream }\end{array}$ & $\begin{array}{c}\text { down } \\
\text { stream }\end{array}$ & other \\
\hline $5 / 19$ & $9(1)$ & 2 & $120(50)$ & $0.32(0.14)$ & 57 & 40 & 3 & 56 & 40 & 4 \\
\hline $5 / 20$ & $12(1)$ & 5 & $173(45)$ & $0.50(0.30)$ & 63 & 33 & 4 & 61 & 15 & 24 \\
\hline $5 / 15$ & $14(1)$ & 2 & $106(30)$ & $0.56(0.26)$ & 58 & 32 & 10 & 55 & 41 & 4 \\
\hline $5 / 13$ & $16(1)$ & 3 & $143(30)$ & $0.42(0.25)$ & 49 & 37 & 14 & 44 & 38 & 18 \\
\hline $5 / 14$ & $19(1)$ & 4 & $178(32)$ & $0.62(0.35)$ & 65 & 23 & 12 & 53 & 35 & 12 \\
\hline $5 / 8$ & $23(0)$ & 2 & 73 (12) & $0.26(0.22)$ & 69 & 24 & 7 & 70 & 30 & 0 \\
\hline $5 / 12$ & $25(1)$ & 3 & $100(15)$ & $0.35(0.21)$ & 53 & 28 & 19 & 61 & 37 & 2 \\
\hline
\end{tabular}


Table 5. Summary of hydraulic conditions at the modular screen, the number and species of fish used for testing, and the percentage of fish that successfully passed over the screen during consecutive 5-minute periods, 2010. Only one steelhead refused to pass over the screen initially, but eventually did so within 10 minutes.

[Q, discharge; AV, approach velocity; SV, sweeping velocity; SD, standard deviation; $\mathrm{cm}$, centimeter; $\mathrm{cm} / \mathrm{s}$, centimeter per second;

\begin{tabular}{cccccccccc} 
& & & & & \multicolumn{5}{c}{ Percentage of observations where fish passed over } \\
the screen
\end{tabular}

\footnotetext{
${ }^{1}$ Values include fish that were prodded from the upper $3 \mathrm{~m}$ of the flume.
} 
Publishing support provided by the U.S. Geological Survey Publishing Network, Tacoma Publishing Service Center

For more information concerning the research in this report, contact the Director, Western Fisheries Research Center

U.S. Geological Survey, 6505 NE 65th Street

Seattle, Washington 98115

http://wfrc.usgs.gov/ 


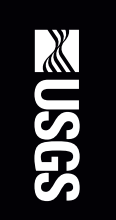

$\underset{\infty}{3}$

믈

옴

몸

흥

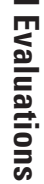

옹

울

峁

옿

종.

끙

궁

궁

c

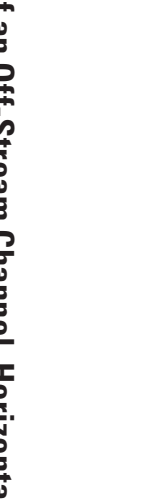

궁

긱

蛋

c

몽

!

음

市

귱

음

응 